\title{
Prognostic Significance of Serum Indoxyl Sulfate and Albumin for Patients with Cardiovascular Disease
}

\author{
Ippei Watanabe, ${ }^{1}$ MD, Junko Tatebe,${ }^{2}$, Takahiro Fujii, ${ }^{1}$ MD, Ryota Noike, ${ }^{1}$ MD, Daiga Saito, ${ }^{1}$ MD, \\ Hideki Koike, ${ }^{1}$ MD, Takayuki Yabe, ${ }^{1}$ MD, Ryo Okubo, ${ }^{1}$ MD, Rine Nakanishi, ${ }^{1}$ MD, Hideo Amano, ${ }^{1}$ MD, \\ Mikihito Toda, ${ }^{1}$ MD, Takanori Ikeda, ${ }^{1}$ MD and Toshisuke Morita, ${ }^{2}$ MD
}

\begin{abstract}
Summary
The progression of renal dysfunction reduces serum albumin and deteriorates the binding capacity of protein-bound uremic toxins. We evaluated the prognostic implications of serum indoxyl sulfate (IS) and albumin levels in patients with cardiovascular disease.

We prospectively enrolled 351 consecutive patients undergoing percutaneous revascularization for coronary artery disease or peripheral artery disease. The primary endpoint was all-cause mortality. Patients were assigned to four groups according to the median levels of serum IS $(0.1 \mathrm{mg} / \mathrm{dL})$ and albumin $(3.9 \mathrm{~g} / \mathrm{dL})$.

During the median follow-up time of 575 days, 16 patients died. The IS level was significantly higher in nonsurvivors $(0.33$ versus $0.85 \mathrm{mg} / \mathrm{dL}, P<0.05)$. On the Kaplan-Meier curve, the high IS/low albumin group presented the highest mortality rate (log-rank test, $P<0.01)$. Cox proportional hazard analysis revealed that high IS/low albumin (hazard ratio (HR): 5.33; 95\% confidence interval (CI): 1.71-16.5; $P<0.01$ ), diastolic pressure (HR: 0.94; 95\% CI: 0.91-0.98; $P<0.01$ ), prior stroke (HR: 4.54; 95\% CI: $1.33-15.4 ; P=0.01$ ), and left ventricular ejection fraction (LVEF) (HR: 0.92; 95\% CI: $0.88-0.96 ; P<0.001)$ were associated with increased mortality. Furthermore, the combination of IS and albumin levels significantly conferred an additive value to LVEF for predicting mortality (C-statistic: 0.69 versus $0.80 ; P<0.001$; net reclassification improvement: $0.83 ; P<0.001$; integrated discrimination improvement: $0.02 ; P=0.02$ ).
\end{abstract}

A lower albumin level adds potentiating effects on IS as a prognostic factor for cardiovascular disease.

(Int Heart J 2019; 60: 129-135)

Key words: Cardio-renal syndrome, Uremic toxin

$\mathrm{T}$ here is a positive correlation between renal disease and cardiovascular disease. ${ }^{1-5)}$ Studies have demonstrated that an increased level of uremic toxins that are associated with the progression of renal dysfunction is involved in the development of atherosclerosis through the induction of oxidative stress. ${ }^{6-8)}$

Indoxyl sulfate (IS) is a protein-bound uremic toxin that is an end metabolite of dietary tryptophan. Recent studies have found that IS is toxic to the cardiovascular system. ${ }^{9,10)}$ Cellular damage in human vascular cells resulting from increased pro-inflammatory responses and the production of reactive oxygen species is a consequence of accumulated IS. ${ }^{11,12)}$ Moreover, IS was found to induce endothelial dysfunction, which promotes atherosclerosis in patients with renal dysfunction. . $^{6,13,14)}$

\section{Editorial p.7}

Of note, there is a close interaction between serum albumin level and uremic toxins, including IS. ${ }^{15)}$ Compared with other uremic toxins, IS binds tightly to albumin. ${ }^{16)}$ For patients with renal dysfunction, however, hypoalbuminemia and oxidation decrease the capacity of IS to bind albumin. ${ }^{17,18)}$ Thus, as renal dysfunction advances, unbound IS is thought to be in excess. Here, we investigate the prognostic effects of serum IS and albumin level in patients with cardiovascular disease.

\section{Methods}

Study population: A total of 351 consecutive patients with cardiovascular disease at Toho University Omori Medical Center (Tokyo, Japan) were enrolled between March 2015 and June 2016 in this study. The inclusion

From the ${ }^{1}$ Division of Cardiovascular Medicine, Department of Internal Medicine, Toho University Faculty of Medicine, Tokyo, Japan and ${ }^{2}$ Department of Laboratory Medicine, Toho University Faculty of Medicine, Tokyo, Japan.

This study was supported in part by Grants-in-Aid (24591074 and 15K09103 to T.I.) for Scientific Research from the Ministry of Education, Culture, Sports, Science and Technology of Japan.

Address for correspondence: Toshisuke Morita, MD, Department of Laboratory Medicine, Toho University Faculty of Medicine, 6-11-1 Omorinishi, Ota-ku, Tokyo 143-8541, Japan. E-mail: toshimrt@med.toho-u.ac.jp

Received for publication February 24, 2018. Revised and accepted April 25, 2018

Released in advance online on J-STAGE November 20, 2018.

doi: 10.1536/ihj.18-116

All rights reserved by the International Heart Journal Association. 
criteria were (1) patients undergoing percutaneous coronary intervention (PCI) for coronary artery disease (CAD), which included acute coronary syndrome (ACS, $n=122$ ) and stable angina pectoris (SAP, $n=186$ ), and (2) patients undergoing percutaneous peripheral intervention (PPI) for peripheral artery disease (PAD, $n=43$ ). Patients with ACS included ST-segment elevation myocardial infarction (STEMI), non-STEMI, and unstable angina pectoris and underwent primary PCI within 12 hours after chest symptoms. ${ }^{19)}$ Patients with SAP, defined as chest pain that had not changed over the preceding 2 months, underwent elective PCI if significant coronary stenosis (lumen obstruction of $>60 \%$ ) was documented. Patients undergoing PPI for symptomatic PAD were included at Rutherford stages 2-5 (Fontaine stages IIb-IV). The ankle-brachial index was routinely used before angiography to confirm the diagnosis of PAD. We performed PCI and PPI according to current guidelines. The study exclusion criteria were (1) death from any cause within 30 days after therapy and (2) active malignancy and inflammatory disease.

Patients were assigned to four groups according to the median levels of IS $(0.1 \mathrm{mg} / \mathrm{dL})$ and albumin $(3.9 \mathrm{~g} /$ dL) (low IS/high albumin, low IS/low albumin, high IS/ high albumin, and high IS/low albumin).

Cardiovascular risk factors, including diabetes, dyslipidemia, hypertension, and current smoking, were defined in accordance with accepted criteria. ${ }^{20-22)}$ Body mass index was calculated according to patient height and weight measured during hospitalization. The Modification of Diet in Renal Disease formula ${ }^{23)}$ was applied for calculating the estimated glomerular filtration rate (eGFR), and eGFR $<60 \mathrm{~mL} /$ minute $/ 1.73 \mathrm{~m}^{2}$ was defined as impaired renal function. ${ }^{24)}$ Left ventricular ejection fraction (LVEF) was measured using the biplanar modified Simpson's rule from apical two- and four-chamber views in echocardiography within 24 hours after admission. ${ }^{25)}$ Serum albumin was measured by the modified bromocresol purple assay using Aqua Auto (Kainos, Tokyo, Japan) with a Hitachi LST 008 automated analyzer (Hitachi HighTechnologies, Tokyo, Japan). All coronary stenting required $100 \mathrm{mg}$ aspirin and $150 \mathrm{mg}$ clopidogrel or $20 \mathrm{mg}$ prasugrel administration before catheterization. Dual antiplatelet therapy was continued for at least 6 months. In the case of peripheral stenting, dual antiplatelet therapy proceeded for at least 1 month. The primary endpoint was death from any cause within 3 years. This study was conducted according to the guidelines of the Declaration of Helsinki and approved by the local ethics committee in the Toho University School of Medicine.

Analysis of serum IS: Serum IS level was measured upon hospital admission. Each serum sample $(10 \mu \mathrm{L})$ was analyzed by reversed-phase high-performance liquid chromatography (Capcell Pak MF Ph-1 SG80S5 4.6 mm ID × $150 \mathrm{~mm}$; SHISEIDO CO., LTD., Tokyo, Japan). The mo-

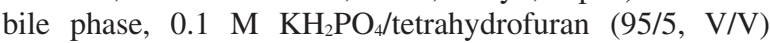
$(\mathrm{pH} 6.5)$, was delivered at a flow rate of $1.0 \mathrm{~mL} / \mathrm{minutes}$ at $37^{\circ} \mathrm{C}$. Serum IS level was determined with fluorescence detection (excitation, $295 \mathrm{~nm}$; emission, $390 \mathrm{~nm}$ ).

Study endpoint: The primary endpoint of this study was all-cause death between 30 days and 3 years after therapy. Clinical follow-up included a review of medical charts and/or telephone contact with patients or their families. Mortality data were collected from the medical records of patients who died at the medical center.

Statistical analysis: Data were analyzed with the Statistical Package for EZR for Windows (Version 1.35, Saitama, Japan). ${ }^{26)}$ The measured data are expressed as mean \pm SD or median and interquartile range. The KolmogorovSmirnov test was applied to test for normal distribution. Continuous variables were compared using the Student's $t$-test. In the case of nonlinearity of data points, they were logarithmically transformed using the base logarithm of 2 . Demographics, traditional risk factors, and clinical outcomes were compared using the Pearson v2 test or the Fisher exact test, as appropriate, for categorical data, and expressed as percentages. Unadjusted cumulative event rates were estimated using Kaplan-Meier curves and compared across groups. Cox proportional hazards models were used to assess univariate and multivariable covariates. The hazard ratio (HR) and confidence interval (CI) were calculated for each factor by Cox proportional hazards analysis. Multivariate analysis included only variables showing $P<0.1$ in the univariate analysis. We also evaluated the discriminative ability of IS added to risk stratification using LVEF measurement. IS was added to LVEF, and the C-statistic was compared with that of LVEF alone. The incremental predictive value of IS to LVEF was assessed by net reclassification improvement (NRI) and integrated discrimination improvement (IDI).

\section{Results}

Patient classification and baseline data: A total of 351 consecutive patients with cardiovascular disease were prospectively enrolled in this study. Baseline clinical etiology included CAD undergoing PCI $(n=308)$ and PAD undergoing PPI $(n=43)$. Table I shows the baseline clinical characteristics by categorization according to the median values of serum IS $(0.10 \mathrm{mg} / \mathrm{dL})$ and albumin $(3.9 \mathrm{~g} /$ $\mathrm{dL})$. Patients in the high IS/low albumin group had a higher prevalence of atrial fibrillation, renal dysfunction, and anemia. More patients were undergoing dialysis in the high IS/high albumin and high IS/low albumin groups than in the other two groups. Patients in the high IS/low albumin group were older and had lower hemoglobin levels. Baseline diastolic blood pressure and LVEF were lower, and the plasma brain natriuretic peptide level was higher in the high IS/low albumin group. These patients were often treated with anticoagulants and loop diuretics. Although the use of baseline statin therapy was statistically equivalent among all the four groups, the levels of total cholesterol and low-density lipoprotein were significantly lower in the high IS/high albumin and high IS/low albumin groups than in the other two groups.

High IS with low albumin level is associated with increased risk of all-cause mortality: During the median follow-up time of 575 days, $4.6 \%$ of patients died $(n=$ 16). The Kaplan-Meier curves for all-cause mortality were significantly different for each group, and the cumulative risk for all-cause mortality was significantly greater for high IS/low albumin (Figure). After adjustment for confounding factors, including age, body mass index, dia- 
Table I. Clinical Characteristics of Patients Categorized by IS and Albumin Levels

\begin{tabular}{|c|c|c|c|c|c|c|}
\hline & $\begin{array}{l}\text { Overall } \\
n=351\end{array}$ & $\begin{array}{c}\text { low IS/high Alb } \\
\text { IS } \leq 0.1 \mathrm{mg} / \mathrm{dL} \\
\text { Alb } \geq 3.9 \mathrm{~g} / \mathrm{dL} \\
n=99\end{array}$ & $\begin{array}{c}\text { low IS/low Alb } \\
\mathrm{IS} \leq 0.1 \mathrm{mg} / \mathrm{dL} \\
\mathrm{Alb}<3.9 \mathrm{~g} / \mathrm{dL} \\
n=75\end{array}$ & $\begin{array}{c}\text { high IS/high Alb } \\
\text { IS }>0.1 \mathrm{mg} / \mathrm{dL} \\
\text { Alb } \geq 3.9 \mathrm{~g} / \mathrm{dL} \\
n=100\end{array}$ & $\begin{array}{c}\text { high IS/low Alb } \\
\text { IS }>0.1 \mathrm{mg} / \mathrm{dL} \\
\mathrm{Alb}<3.9 \mathrm{~g} / \mathrm{dL} \\
n=77\end{array}$ & $P$ value \\
\hline Albumin (g/dL) & $3.83 \pm 0.53$ & $4.2 \pm 0.2$ & $3.4 \pm 0.4$ & $4.2 \pm 0.3$ & $3.3 \pm 0.4$ & $<0.001$ \\
\hline IS, $\mathrm{mg} / \mathrm{dL}$ & $0.35 \pm 0.88$ & $0.55 \pm 0.03$ & $0.05 \pm 0.03$ & $0.59 \pm 1.15$ & $0.70 \pm 1.20$ & $<0.001$ \\
\hline Age, years & $66.3 \pm 11.3$ & $63.0 \pm 12.5$ & $66.7 \pm 11.2$ & $65.9 \pm 10.5$ & $70.4 \pm 9.5$ & $<0.001$ \\
\hline Male, $n(\%)$ & $265(75.5)$ & $72(72.7)$ & $55(73.3)$ & $77(77.0)$ & $61(79.2)$ & 0.70 \\
\hline Hypertension, $n(\%)$ & $191(54.4)$ & $48(48.5)$ & $47(62.7)$ & $52(52.0)$ & $44(57.1)$ & 0.43 \\
\hline Diabetes, $n(\%)$ & $127(36.2)$ & $27(27.2)$ & $27(36.0)$ & $44(44.0)$ & $29(37.7)$ & 0.13 \\
\hline Dyslipidemia, $n(\%)$ & $136(38.7)$ & $42(42.4)$ & $31(41.3)$ & $41(41.0)$ & $22(28.6)$ & 0.20 \\
\hline Current smoker, $n(\%)$ & $241(68.7)$ & $64(64.6)$ & $56(74.7)$ & $66(66.0)$ & $55(71.4)$ & 0.61 \\
\hline CKD, $n(\%)$ & $148(42.1)$ & $23(23.2)$ & $28(37.3)$ & $41(41.0)$ & $56(72.7)$ & $<0.001$ \\
\hline Dialysis, $n(\%)$ & $31(8.8)$ & $0(0)$ & $0(0)$ & $14(14.0)$ & $17(22.1)$ & $<0.001$ \\
\hline Anemia, $n(\%)$ & $199(56.7)$ & $41(41.4)$ & $44(58.7)$ & $49(49.0)$ & $65(84.4)$ & $<0.001$ \\
\hline Atrial fibrillation, $n(\%)$ & $31(8.8)$ & $5(5.0)$ & $3(4.0)$ & $14(14.0)$ & $9(11.7)$ & 0.04 \\
\hline PCI, $n(\%)$ & $308(87.7)$ & $93(93.9)$ & $68(90.6)$ & $86(86.0)$ & $61(79.2)$ & 0.02 \\
\hline PPI, $n(\%)$ & $43(12.2)$ & $6(6.0)$ & $7(9.3)$ & $14(14.0)$ & $16(20.8)$ & 0.02 \\
\hline Prior stroke, $n(\%)$ & $24(6.8)$ & $3(3.0)$ & $5(6.7)$ & $8(8.0)$ & $8(10.4)$ & 0.24 \\
\hline BMI, $\mathrm{kg} / \mathrm{m}^{2}$ & $24.5 \pm 9.0$ & $24.4 \pm 2.9$ & $23.3 \pm 4.8$ & $25.6 \pm 10.9$ & $24.7 \pm 13.8$ & 0.42 \\
\hline LVEF, \% & $61.0 \pm 14.0$ & $62.7 \pm 12.8$ & $61.1 \pm 15.0$ & $63.2 \pm 13.3$ & $56.0 \pm 14.6$ & 0.003 \\
\hline Heart rate, bpm & $75.3 \pm 16.0$ & $76.8 \pm 16.9$ & $78.9 \pm 19.9$ & $75.9 \pm 16.1$ & $70.6 \pm 14.9$ & 0.03 \\
\hline $\mathrm{SBP}, \mathrm{mmHg}$ & $137.2 \pm 27.3$ & $139.6 \pm 29.2$ & $135.5 \pm 26.8$ & $139.6 \pm 28.1$ & $133.0 \pm 26.1$ & 0.32 \\
\hline $\mathrm{DBP}, \mathrm{mmHg}$ & $74.9 \pm 16.8$ & $78.3 \pm 18.4$ & $73.9 \pm 16.9$ & $75.9 \pm 16.1$ & $70.6 \pm 14.9$ & 0.02 \\
\hline $\mathrm{TC}, \mathrm{mg} / \mathrm{mL}$ & $181.1 \pm 56.2$ & $195.1 \pm 61.5$ & $182.5 \pm 62.9$ & $172.4 \pm 48.6$ & $173.5 \pm 47.2$ & 0.02 \\
\hline $\mathrm{LDL}, \mathrm{mg} / \mathrm{dL}$ & $111.7 \pm 43.9$ & $120.7 \pm 50.4$ & $114.7 \pm 50.5$ & $104.6 \pm 34.3$ & $105.9 \pm 36.6$ & 0.04 \\
\hline $\mathrm{HDL}, \mathrm{mg} / \mathrm{dL}$ & $48.6 \pm 16.5$ & $50.6 \pm 17.3$ & $49.1 \pm 18.0$ & $48.1 \pm 16.9$ & $46.4 \pm 13.4$ & 0.38 \\
\hline $\mathrm{TG}, \mathrm{mg} / \mathrm{dL}$ & $139.6 \pm 84.2$ & $153.9 \pm 78.0$ & $119.3 \pm 90.4$ & $147.9 \pm 78.4$ & $131.6 \pm 89.8$ & 0.04 \\
\hline $\mathrm{TP}, \mathrm{g} / \mathrm{dL}$ & $7.2 \pm 0.6$ & $7.6 \pm 0.5$ & $6.9 \pm 0.7$ & $7.6 \pm 0.5$ & $6.8 \pm 0.6$ & $<0.001$ \\
\hline $\mathrm{UA}, \mathrm{mg} / \mathrm{dL}$ & $5.8 \pm 1.5$ & $5.8 \pm 1.5$ & $5.8 \pm 1.5$ & $5.6 \pm 1.5$ & $5.9 \pm 1.7$ & 0.52 \\
\hline Hemoglobin, g/dL & $13.1 \pm 1.9$ & $13.9 \pm 1.7$ & $12.9 \pm 1.9$ & $13.3 \pm 1.8$ & $11.9 \pm 1.7$ & $<0.001$ \\
\hline $\mathrm{HbA} 1 \mathrm{c}, \%$ & $6.3 \pm 1.1$ & $6.2 \pm 1.1$ & $6.6 \pm 1.4$ & $6.3 \pm 1.0$ & $6.4 \pm 1.1$ & 0.2 \\
\hline $\mathrm{BNP}, \mathrm{pg} / \mathrm{mL}$ & $194.1 \pm 471.4$ & $82.1 \pm 154.0$ & $189.4 \pm 269.0$ & $152.6 \pm 404.6$ & $394.1 \pm 806.2$ & $<0.001$ \\
\hline Creatinine, $\mathrm{mg} / \mathrm{dL}$ & $1.55 \pm 2.31$ & $0.84 \pm 0.23$ & $0.88 \pm 0.20$ & $1.87 \pm 2.59$ & $2.74 \pm 3.64$ & $<0.001$ \\
\hline eGFR, $\mathrm{mL} /$ minute $/ 1.73 \mathrm{~m}^{2}$ & $60.7 \pm 25.1$ & $72.6 \pm 19.1$ & $66.7 \pm 18.3$ & $56.9 \pm 26.8$ & $44.9 \pm 26.2$ & $<0.001$ \\
\hline \multicolumn{7}{|l|}{ Preoperative medications } \\
\hline Beta blockers, $n(\%)$ & $98(27.9)$ & $19(19.2)$ & $20(26.7)$ & $29(29.0)$ & $30(39.0)$ & 0.04 \\
\hline RAAS inhibitors, $n(\%)$ & $166(47.2)$ & $43(43.4)$ & $35(46.7)$ & $50(50.0)$ & $38(49.4)$ & 0.84 \\
\hline $\mathrm{CCB}, n(\%)$ & $112(31.9)$ & $34(34.3)$ & $19(25.3)$ & $32(32.0)$ & $27(35.1)$ & 0.44 \\
\hline Statins, $n(\%)$ & $121(34.4)$ & $35(35.4)$ & $28(37.3)$ & $40(40.0)$ & $18(23.4)$ & 0.12 \\
\hline Anticoagulants, $n(\%)$ & $33(9.4)$ & $5(5.1)$ & $1(1.3)$ & $12(12.0)$ & $15(19.5)$ & $<0.001$ \\
\hline Loop diuretics, $n(\%)$ & $37(10.5)$ & $1(1.0)$ & $6(8.0)$ & $9(9.0)$ & $21(27.3)$ & $<0.001$ \\
\hline \multicolumn{7}{|l|}{ Postoperative medications } \\
\hline Beta blockers, $n(\%)$ & $98(27.9)$ & $59(59.6)$ & $52(69.3)$ & $47(47.0)$ & $49(63.6)$ & 0.03 \\
\hline RAAS inhibitors, $n(\%)$ & $256(72.9)$ & $75(75.8)$ & $63(84.0)$ & $66(66.0)$ & $52(63.6)$ & 0.05 \\
\hline $\mathrm{CCB}, n(\%)$ & $110(31.3)$ & $35(35.4)$ & $18(24.0)$ & $36(36.0)$ & $21(67.5)$ & 0.19 \\
\hline Statins, $n(\%)$ & $215(61.2)$ & $70(70.7)$ & $52(69.3)$ & $56(56.0)$ & $37(48.1)$ & 0.006 \\
\hline Anticoagulants, $n(\%)$ & $43(12.2)$ & $10(10.1)$ & $6(8.0)$ & $13(13.0)$ & $14(18.2)$ & 0.21 \\
\hline Loop diuretics, $n(\%)$ & $61(17.3)$ & $8(8.1)$ & $15(20.0)$ & $12(12.0)$ & $26(33.8)$ & $<0.001$ \\
\hline DAPT, $n(\%)$ & $316(90.0)$ & $93(93.9)$ & $67(89.3)$ & $91(91.0)$ & $65(84.4)$ & 0.05 \\
\hline
\end{tabular}

Alb indicates albumin; IS, indoxyl sulfate; CKD, chronic kidney disease; PCI, percutaneous coronary intervention; PPI, percutaneous peripheral intervention; BMI, body mass index; LVEF, left ventricular ejection fraction; SBP, systolic blood pressure; DBP, diastolic blood pressure; TC, total cholesterol; LDL, low-density lipoprotein; HDL, high-density lipoprotein; TG, triglyceride; TP, total protein; UA, uric acid; BNP, brain natriuretic peptide; eGFR, estimated glomerular filtration rate; RAAS inhibitors, renin angiotensin aldosterone system inhibitors; CCB, calcium channel blockers; and DAPT, dual antiplatelet therapy.

stolic pressure, LVEF, hemoglobin, dialysis, prior stroke, eGFR, brain natriuretic peptide, uric acid, coronary intervention, and peripheral intervention, Cox proportional hazards analysis indicated that high IS/low albumin was an independent risk factor for all-cause mortality (Table II).
Discrimination and reclassification analysis of serum IS and albumin: The values of the C-statistic for predicting all-cause mortality were separately calculated for LVEF (0.69) and IS (0.65) (Table III). Although adding the IS level to the LVEF analysis did not significantly improve the C-statistic (0.72), the result with a combination 


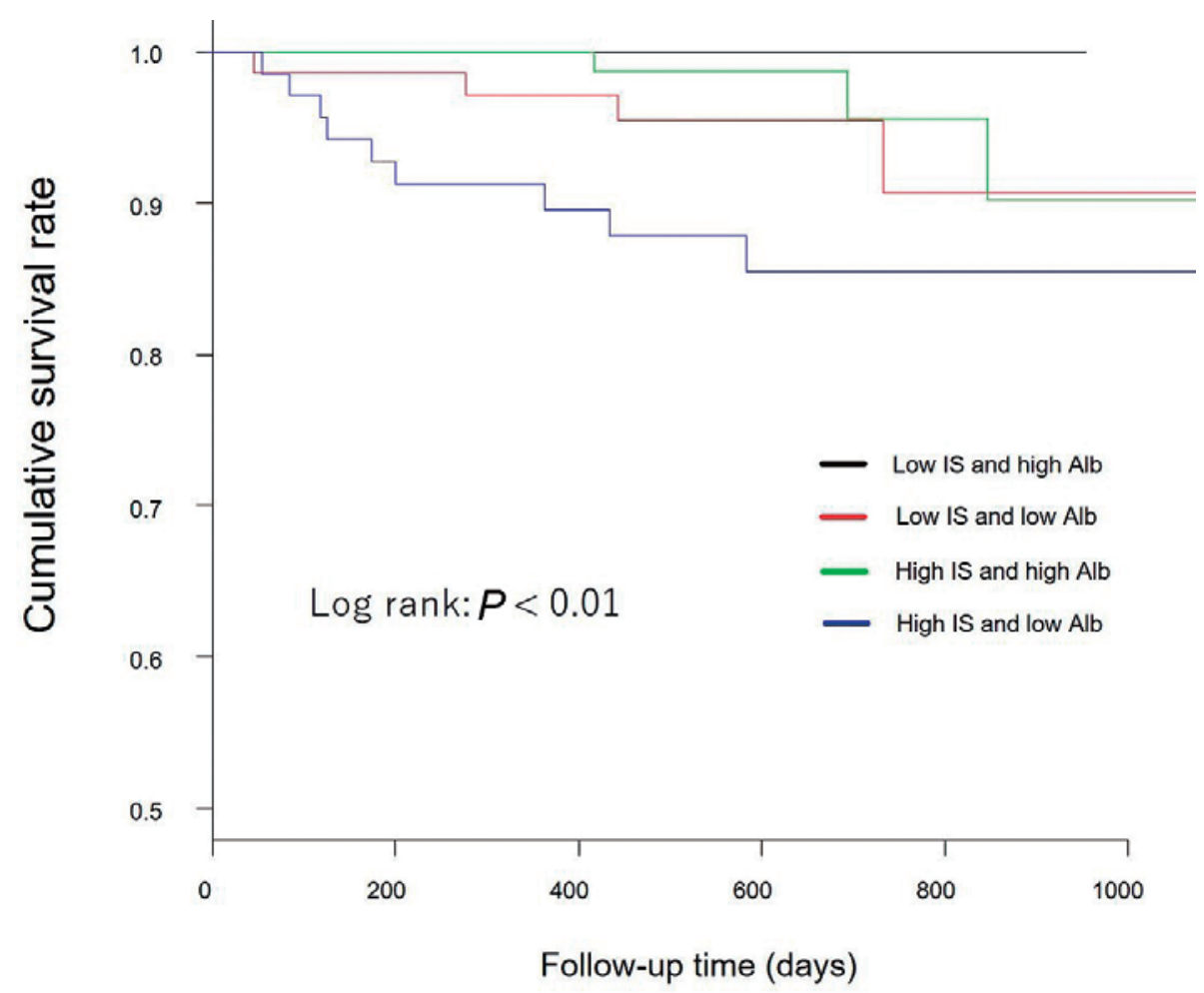

\begin{tabular}{lcccccr}
\multicolumn{7}{c}{ Number at risk } \\
Low IS and high Alb & 99 & 95 & 78 & 45 & 8 & 0 \\
Low IS and low Alb & 75 & 66 & 58 & 38 & 17 & 2 \\
High IS and high Alb & 100 & 96 & 82 & 45 & 21 & 1 \\
High IS and low Alb & 77 & 61 & 52 & 33 & 12 & 1
\end{tabular}

Figure. Kaplan-Meier curve for mortality according to serum IS and albumin level quartile.

of LVEF together with both IS and albumin levels was significantly greater than that for LVEF alone (0.69 versus $0.80, P<0.001)$. The inclusion of IS and the IS/albumin combination led to a significantly better categorization of patients $(47 \%$ and $83 \%$ of them were reclassified, respectively). The IDI indices for IS and the IS/albumin combination were $0.01(P=0.23)$ and $0.02(P=0.02)$, respectively.

\section{Discussion}

Our results demonstrate that the IS level has the potential to serve as a prognostic marker when combined with the albumin level for patients with cardiovascular disease. Among the four groups categorized by the serum IS and albumin levels, patients assigned to the high IS/low albumin group were more highly affected by cardiovascular risk factors, including older age, anemia, and low LVEF, than patients in the other groups. As demonstrated by Kaplan-Meier curves, patients in the high IS/low albumin group showed significantly higher mortality rates than those in the other groups. In addition, this combination was found to be a prognostic factor in the multivariate analysis adjusted for multiple confounders.

The progression of renal disease is inseparable from cardiovascular disease as a prognostic factor, and their in- teractions (called "cardio-renal syndrome") have recently become a global healthcare concern. ${ }^{27,28)}$ The accumulation of uremic solutes may play an important role in the etiology of cardio-renal syndrome. IS is a protein-bound uremic toxin that was recently found to be damaging to the cardiovascular system. ${ }^{11,12,29,30)}$ Our previous reports identified IS-induced atherosclerotic-related changes such as inflammation and premature senescence in human endothelial cells through activation of the aryl hydrocarbon receptor. ${ }^{31)}$ To our knowledge, however, no studies have shown whether serum IS and albumin levels can predict the outcome of cardiovascular disease patients with widely varying renal function. An increase in free IS with the progression of chronic kidney disease may be key to explaining our results. Considering the molecular structure of albumin, it seems unlikely that the bound form of IS activates the signal transduction pathway that includes the aryl hydrocarbon receptor. Therefore, free IS may be a better indicator of the potential toxicity of uremic solutes for patients with chronic kidney disease, as tissues are exposed to free solute. ${ }^{32,33)}$ Lin, et al. reported the association between free IS and endothelial dysfunction in patients with renal dysfunction. ${ }^{34)}$ In addition, the free IS level was associated with in-stent restenosis after PCI. ${ }^{35)}$ Interestingly, our results are consistent with the study by Shafi, et $a l$., which reported that the total IS level can predict the 
Table II. Predictors of Mortality

\begin{tabular}{|c|c|c|c|c|}
\hline & \multicolumn{2}{|c|}{ Univariate analysis } & \multicolumn{2}{|c|}{ Multivariate analysis } \\
\hline & $\mathrm{HR}, 95 \% \mathrm{CI}$ & $P$ value & $\mathrm{HR}, 95 \% \mathrm{CI}$ & $P$ value \\
\hline Female & $2.34,0.52-10.5$ & 0.27 & & \\
\hline Age & $1.06,0.99-1.12$ & 0.05 & & \\
\hline Atrial fibrillation & $0.64,0.08-4.89$ & 0.67 & & \\
\hline Heart rate & $1.01,0.99-1.04$ & 0.37 & & \\
\hline SBP & $0.99,0.97-1.01$ & 0.26 & & \\
\hline DBP & $0.94,0.91-0.97$ & $<0.001$ & $0.94,0.91-0.98$ & $<0.01$ \\
\hline Hypertension & $0.83,0.31-2.27$ & 0.72 & & \\
\hline Diabetes & $1.30,0.48-3.51$ & 0.59 & & \\
\hline Dyslipidemia & $0.71,0.24-2.08$ & 0.53 & & \\
\hline Current smoker & $1.96,0.55-7.02$ & 0.3 & & \\
\hline Prior stroke & $5.25,1.55-17.8$ & $<0.01$ & $4.54,1.33-15.4$ & 0.01 \\
\hline BMI & $0.91,0.83-0.99$ & 0.03 & & \\
\hline Hemoglobin & $5.43,1.24-23.9$ & 0.03 & & \\
\hline UA & $0.73,0.52-1.02$ & 0.06 & $0.69,0.48-0.98$ & 0.04 \\
\hline $\mathrm{TC}$ & $0.99,0.99-1.00$ & 0.93 & & \\
\hline TP & $0.63,0.30-1.33$ & 0.22 & & \\
\hline BNP & $4.66,2.08-10.5$ & $<0.001$ & & \\
\hline eGFR & $0.96,0.95-0.99$ & 0.001 & & \\
\hline Dialysis & $7.44,2.50-22.2$ & $<0.01$ & & \\
\hline LVEF & $0.96,0.93-0.99$ & 0.01 & $0.92,0.88-0.96$ & $<0.001$ \\
\hline PCI & $0.38,0.13-1.13$ & 0.08 & & \\
\hline PPI & $3.55,1.17-10.8$ & 0.03 & $5.42,1.26-23.3$ & 0.02 \\
\hline low IS/high Alb & - & - & - & - \\
\hline low IS/low Alb & $1.20,0.38-3.82$ & 0.76 & & \\
\hline high IS/high Alb & $0.57,0.16-2.03$ & 0.38 & & \\
\hline high IS/low Alb & $5.05,1.81-14.0$ & $<0.01$ & $5.33,1.71-16.5$ & $<0.01$ \\
\hline
\end{tabular}

HR indicates hazard ratio; 95\% CI, 95\% confidence interval; SBP, systolic blood pressure; DBP, diastolic blood pressure; BMI, body mass index; TC, total cholesterol; TP, total protein; UA, uric acid; BNP, brain natriuretic peptide; eGFR, estimated glomerular filtration ratio; CKD, chronic kidney disease; LVEF, left ventricular ejection fraction; PCI, percutaneous coronary intervention; and PPI, percutaneous peripheral intervention.

Table III. Discrimination of the Predictive Model for Mortality by C-statistic, NRI, and IDI

\begin{tabular}{lcccccc}
\hline All-cause death & C-statistic & $P$ value & NRI & $P$ value & IDI & $P$ value \\
\hline LVEF & 0.69 & Ref. & - & Ref. & - & Ref \\
LVEF + IS & 0.72 & 0.23 & 0.47 & 0.04 & 0.01 & 0.23 \\
LVEF + IS + Alb & 0.80 & $<0.001$ & 0.83 & $<0.001$ & 0.02 & 0.02 \\
\hline
\end{tabular}

NRI indicates net reclassification improvement; IDI, integrated discrimination improvement; LVEF, left ventricular ejection fraction; IS, indoxyl sulfate; and Alb, albumin.

cardiovascular outcomes of patients undergoing hemodialysis. ${ }^{33)}$ The authors emphasized the prognostic importance of an elevated level of free IS concomitant with a lower albumin level. A lower albumin level may increase free IS through competition with other accumulating protein-bound solutes. In addition, a low albumin level was associated with the oxidation of binding sites specific for uremic toxins, portending a reduced capacity to bind uremic toxins. ${ }^{18,36)}$ Therefore, consideration of serum albumin status may be required when assessing the IS-induced toxicity of the cardiovascular system.

Finally, we investigated the incremental value of IS in standard risk prediction in the reclassification analysis. The predictive value of IS alone or in combination with albumin was added to that of LVEF. There was only a tendency of serum IS level alone to improve risk stratification. In contrast, we demonstrated that the combination of IS and albumin levels brought significant additive prognostic value to LVEF.

Study limitations: This study has the following limitations. First, it is a single-center, observational cohort study of a relatively small population. Second, the serum IS level was determined at a single point. Investigation using serial determination of the IS level for each patient may provide better insight for risk stratification. Third, nutritional status might have provided important additional outcome information. Such analyses were not possible owing to the limited valid data on nutritional status. 


\section{Conclusions}

Serum IS level in combination with a lower albumin level is a prognostic factor for patients with cardiovascular disease. Our data provide the basis for future investigations of the impact of free IS on cardio-renal syndrome.

\section{Disclosures}

Conflicts of interest: The authors received no funding from any agency in the public, commercial, or not-forprofit sectors and have no conflicts of interest to declare.

\section{References}

1. Ronco C, Haapio M, House AA, Anavekar N, Bellomo R. Cardiorenal syndrome. J Am Coll Cardiol 2008; 52: 1527-39.

2. Sarnak MJ, Levey AS, Schoolwerth AC, et al. Kidney disease as a risk factor for development of cardiovascular disease: a statement from the American Heart Association Councils on Kidney in Cardiovascular Disease, High Blood Pressure Research, Clinical Cardiology, and Epidemiology and Prevention. Hypertension 2003; 42: 1050-65.

3. Parsh J, Seth M, Aronow $\mathrm{H}$, et al. Choice of Estimated Glomerular Filtration Rate Equation Impacts Drug-Dosing Recommendations and Risk Stratification in Patients With Chronic Kidney Disease Undergoing Percutaneous Coronary Interventions. J Am Coll Cardiol 2015; 65: 2714-23.

4. Nakahigashi M, Tsukaguchi H, Morimoto S, et al. Determinants of the Change in Arterial Stiffness in Peritoneal Dialysis Patients. Int Heart J 2017; 58: 915-25.

5. Nakano Y, Mizuno T, Niwa T, et al. Impact of Continuous Administration of Tolvaptan on Preventing Medium-Term Worsening Renal Function and Long-Term Adverse Events in Heart Failure Patients with Chronic Kidney Disease. Int Heart J 2018; 59: $105-11$.

6. Toyoda S, Kikuchi M, Komatsu T, et al. Impact of the oral adsorbent AST-120 on oxidative stress and uremic toxins in highrisk chronic kidney disease patients. Int J Cardiol 2014; 177: 705-7.

7. Lekawanvijit S, Kompa AR, Wang BH, Kelly DJ, Krum H. Cardiorenal syndrome: the emerging role of protein-bound uremic toxins. Circ Res 2012; 111: 1470-83.

8. Rossi M, Campbell KL, Johnson DW, et al. Protein-bound uremic toxins, inflammation and oxidative stress: a cross-sectional study in stage 3-4 chronic kidney disease. Arch Med Res 2014; 45: 309-17.

9. Yoshikawa D, Ishii H, Suzuki S, et al. Plasma Indoxyl Sulfate and Estimated Glomerular Filtration Rate. Circ J 2014; 78 : 2477-82.

10. Shimazu S, Hirashiki A, Okumura T, et al. Association between indoxyl sulfate and cardiac dysfunction and prognosis in patients with dilated cardiomyopathy. Circ J 2013; 77: 390-6.

11. Ito S, Osaka M, Higuchi Y, Nishijima F, Ishii H, Yoshida M. Indoxyl sulfate induces leukocyte-endothelial interactions through up-regulation of E-selectin. J Biol Chem 2010; 285: 38869-75.

12. Hung SC, Kuo KL, Huang HL, et al. Indoxyl sulfate suppresses endothelial progenitor cell-mediated neovascularization. Kidney Int 2016; 89: 574-85.

13. Hsu CC, Lu YC, Chiu CA, et al. Levels of indoxyl sulfate are associated with severity of coronary atherosclerosis. Clin Invest Med 2013; 36: E42-9.

14. Yu M, Kim YJ, Kang DH. Indoxyl sulfate-induced endothelial dysfunction in patients with chronic kidney disease via an induction of oxidative stress. Clin J Am Soc Nephrol 2011; 6: 309.
15. Watanabe H, Noguchi T, Miyamoto Y, et al. Interaction between two sulfate-conjugated uremic toxins, p-cresyl sulfate and indoxyl sulfate, during binding with human serum albumin. Drug Metab Dispos 2012; 40: 1423-8.

16. Deltombe O, de Loor H, Glorieux G, et al. Exploring binding characteristics and the related competition of different proteinbound uremic toxins. Biochimie 2017; 139: 20-6.

17. Rueth M, Lemke HD, Preisinger C, et al. Guanidinylations of albumin decreased binding capacity of hydrophobic metabolites. Acta Physiol (Oxf) 2015; 215: 13-23.

18. Nagumo K, Tanaka M, Chuang VT, et al. Cys34-cysteinylated human serum albumin is a sensitive plasma marker in oxidative stress-related chronic diseases. PLoS One 2014; 9: e85216.

19. Task Force on the management of ST-segment elevation acute myocardial infarction of the European Society of Cardiology (ESC), Steg PG, James SK, Atar D, et al. ESC Guidelines for the management of acute myocardial infarction in patients presenting with ST-segment elevation. Eur Heart J 2012; 33: 2569619.

20. Ohman EM, Bhatt DL, Steg PG, et al. The REduction of Atherothrombosis for Continued Health (REACH) Registry: an international, prospective, observational investigation in subjects at risk for atherothrombotic events-study design. Am Heart J 2006; 151: 786 .

21. National Cholesterol Education Program Expert Panel on Detection E, Treatment of High Blood Cholesterol in A. Third Report of the National Cholesterol Education Program (NCEP) Expert Panel on Detection, Evaluation, and Treatment of High Blood Cholesterol in Adults (Adult Treatment Panel III) final report. Circulation 2002; 106: 3143-421.

22. Parikh NI, Gona P, Larson MG, et al. Long-term trends in myocardial infarction incidence and case fatality in the National Heart, Lung, and Blood Institute's Framingham Heart study. Circulation 2009; 119: 1203-10.

23. Zamora E, Lupon J, Vila J, et al. Estimated glomerular filtration rate and prognosis in heart failure: value of the Modification of Diet in Renal Disease Study-4, chronic kidney disease epidemiology collaboration, and cockroft-gault formulas. J Am Coll Cardiol 2012; 59: 1709-15.

24. Matsuo S, Imai E, Horio M, et al. Revised equations for estimated GFR from serum creatinine in Japan. Am J Kidney Dis 2009; 53: 982-92.

25. Krumholz HM, Anderson JL, Brooks NH, et al. ACC/AHA clinical performance measures for adults with ST-elevation and non-ST-elevation myocardial infarction: a report of the American College of Cardiology/American Heart Association Task Force on Performance Measures (Writing Committee to Develop Performance Measures on ST-Elevation and Non-STElevation Myocardial Infarction). Circulation 2006; 113: 73261.

26. Kanda Y. Investigation of the freely available easy-to-use software 'EZR' for medical statistics. Bone Marrow Transplant 2013; 48: 452-8

27. Bock JS, Gottlieb SS. Cardiorenal syndrome: new perspectives. Circulation 2010; 121: 2592-600

28. Zhang J, Bottiglieri T, McCullough PA. The Central Role of Endothelial Dysfunction in Cardiorenal Syndrome. Cardiorenal Med 2017; 7: 104-17.

29. Hung SC, Kuo KL, Wu CC, Tarng DC. Indoxyl Sulfate: A Novel Cardiovascular Risk Factor in Chronic Kidney Disease. J Am Heart Assoc 2017; 6: e005022.

30. Tumur Z, Shimizu H, Enomoto A, Miyazaki H, Niwa T. Indoxyl sulfate upregulates expression of ICAM-1 and MCP-1 by oxidative stress-induced NF-kappaB activation. Am J Nephrol 2010; 31: 435-41.

31. Watanabe I, Tatebe J, Namba S, Koizumi M, Yamazaki J, Morita T. Activation of Aryl Hydrocarbon Receptor Mediates Indoxyl Sulfate-Induced Monocyte Chemoattractant Protein-1 Expression in Human Umbilical Vein Endothelial Cells. Circ J 2013; 77: 224-30. 
32. Shafi T, Meyer TW, Hostetter TH, et al. Free Levels of Selected Organic Solutes and Cardiovascular Morbidity and Mortality in Hemodialysis Patients: Results from the Retained Organic Solutes and Clinical Outcomes (ROSCO) Investigators. PLoS One 2015; 10: e0126048.

33. Shafi T, Sirich TL, Meyer TW, et al. Results of the HEMO Study suggest that p-cresol sulfate and indoxyl sulfate are not associated with cardiovascular outcomes. Kidney Int 2017; 92: 1484-92.

34. Lin CJ, Wu V, Wu PC, Wu CJ. Meta-Analysis of the Associa- tions of p-Cresyl Sulfate (PCS) and Indoxyl Sulfate (IS) with Cardiovascular Events and All-Cause Mortality in Patients with Chronic Renal Failure. PLoS One 2015; 10: e0132589.

35. Tsai ML, Hsieh IC, Hung CC, Chen CC. Serum free indoxyl sulfate associated with in-stent restenosis after coronary artery stentings. Cardiovasc Toxicol 2015; 15: 52-60.

36. Klammt S, Wojak HJ, Mitzner A, et al. Albumin-binding capacity $(\mathrm{ABiC})$ is reduced in patients with chronic kidney disease along with an accumulation of protein-bound uraemic toxins. Nephrol Dial Transplant 2012; 27: 2377-83. 